Psychotherapeut

https://doi.org/10.1007/s00278-022-00580-3

(C) The Author(s), under exclusive licence to Springer Medizin Verlag $\mathrm{GmbH}$, ein Teil von Springer Nature 2022

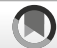

\section{Erratum zu: Die Sprache der Psychotherapeut*innen}

\section{Systematischer Review zum Zusammenhang semantischer Merkmale mit Therapiebeziehung und -ergebnis}

\author{
L. M. Steinert · S. Gries · D. Kästner · S. Wulf · A. Molitor · A. Gumz \\ Psychologische Hochschule Berlin, Berlin, Deutschland
}

\section{Erratum zu:}

Psychotherapeut 2022

https://doi.org/10.1007/s00278-022-

00570-5

In dem ursprünglichen Artikel wurde der zitierte Autorenname de Felice versehentlich verkürzt genannt: Felice.

Bitte beachten Sie die korrigierte Schreibweise in Text, Abb. 2, Literaturverzeichnis und dem zusätzlichen Onlinematerial: de Felice.

Der vollständige und korrigierten Artikel steht Ihnen auf www.springermedizin. de zur Verfügung. Bitte geben Sie dort den Beitragstitel in die Suche ein.

\section{Korrespondenzadresse}

L. M. Steinert, M.Sc. Psychologie Psychologische Hochschule Berlin Am Köllnischen Park 2, 10179 Berlin, Deutschland I.steinert@tp.phb.de
Die Online-Version des Originalartikels ist unter https://doi.org/10.1007/s00278-022-00570-5 zu finden. 